Conclusion.

From the short account which I have been able to give vou of the progress of surgery from Hunter's day to ours, it will be seen that the actual technique employed in the performance of surgical operations, and the results which can be obtained thereby, have reached a very high stage of perfection. It does not appear to me that we can expect in the future such great progress to be made in the details of the performance of operations themselves, and the amelioration of the discomforts directly resulting therefrom. In my opinion the main direction of advance of surgery in the future will be along biochemical and biophysical lines, both as regards diagnosis and treatment. If this assumption be correct, it is essential that the medical student and the medical practitioner of the future should pay increased attention to all biochemical and biophysical problems, both in normal and in diseased conditions.

Owing to the length of the curriculum and the multiplicity of subjects which the student of medicine of the present day has to pass through, there is a tendency for parts of the curriculum to be forgotten after the examination in it has been passed. Consequently the application of physiology in the investigation of disease is too often neglected, and a student thereby is encouraged to acquire surgical knowledge-especially diagnosis-in a somewhat empirical manner. At the present time, however, there is a tendency in every modern school of medicine to give courses of "applied physiology and applied anatomy" during the later and clinical part of a student's career.

\section{THEORIES OF SUGGESTION.*} $B \mathrm{BY}$

WILLIAM BROWN, M.A., M.D.Oxon., D.Sc., M.R.C.P.LoND.

WILDE READER IN MENTAL PHILOSOPHY IN THE UNIVERSITY OF OXFORD; HONORARY CONSULTING PSYCHOLOGIST, BETHLEM ROYAL HOSPITAL; PSYCHOTHERAPIST, KING'S COLLEGE HOSPITAL, LONDON.

THF word "suggestion" has been used in educational, scientific, and medical literature in slightly different senses. In the writings of educationists and purely scientific psychologists it has been used to indicate a general kind of influence brought to bear on the mind, an influence which is other than that of logical or rational argument. The mind can be influenced rationally and also irrationally. 13ationally, it is influenced, for example, when a child is taught the fifth proposition of Euclidt, in learning to understand the steps one by one in the right sequence and in the right connexion; but the child can be influenced non-rationally, in its learning of this and other school sibjects, by virtue of its general mental attitude towards the teacher, by the views on life of its fellow students, even by the beauty or ugliness of the rooms and buildings in which it is taught, by the climate, by the fact of the weather being fine or dull, and in a hundred other ways. These are non-rational, although not necessarily irrational, influences. They may not be contrary to reason, but they are independent of reason so far as the child individually is concerned. We may regard this class of non-rational influence as influence by suggestion.

Again, the child may be misled in his reasoning process and may fall into error. Many of the conditions under which he falls into error can be put under the same heading of suggestion. In a general educational way we mav use the term suggestion in a wide sense which covers all nonrational and includes irrational modes of influencing the mind. An individual may be influenced by inanimate objects, by social conditions, or by his fellows, not only non-rationally, but also unwittingly - that is, without realizing that he is being influenced. The weather may be depressing, and his fundamental mood may follow suit without his being explicitly aware of the fact; the influence

* A paper read before the Section of Psychiatry, Royal Society of Medicine, on January 10th, 1928, and published by permission of the honorary editors of the Society.

t The name, pons asinoruin, given to this proposition may exert a suggestive effect upon the child, in one or other of two ways, according to his temnerament-namely, discouragement, or as a challenge to a
more determined attack. there is an influence of suggestion. It may be considered a rational influence if he observes in the morning that the weather is bad, and infers from it (on the basis of previous experience) that he will have a bad day and will not be able to work so effectively as usual. But that view is not necessarily a true view; he may be mistaken in it. Even if it is a true view, so that the result is rational, it is not necessarily the work of reason.

The word suggestion in pure psychology has been used in an even wider sense. In Professor (i. F. Stout's Analytic Psychology there is a chapter headed "Relative Suggestion," but what he is referring to there is the effect of pre-formed associations on the activity of the mind. Certain experiences have been passed through and retained in memory, and if one experience is repeated it tends to call up the memory of another. One experience "suggests" the memory of another experience. Suggestion, then, may work according to the rules of association, either of contiguity or of similarity; that is a very wide use of the term. An officer's gesture may suggest a certain movement to the platoon under his command, and they may spontaneously move accordingly without having received a definite verbal order. The response to the command may be regarded as due to suggestion. It is not necessarily rational-not a form of persuasion, which is the word to use in speaking of the process of influencing a person by rational means. Giving a command or making a request may be, but is not necessarily, a rational method of influence. In its essence a rational method, it may on some particular occasion be either rational or non-rational. It should probably be classed under the general heading of suggestion, taking the word in its widest sense.

From these uses of the term suggestion-a suggestion which involves a non-rational influencing of the mindwe pass to the more medical side of the subject. In psychological medicine the use of suggestion has developed out of the earlier use of hypnotic influence.

I must first emphasize the fact that hypnotism and suggestion are not the same thing. The state of hypnosis is a state of mental dissociation, in which certain interests of the subject's mind may be appealed to while other parts of the mind remain in abeyance. When a person is hypnotized he is more ready to respond to the influence of the hypnotist because the dissociation of his mind prevents him from being able to call upon his reserves-to bring up other considerations. The hypnotic subject receives a command or request from the hypnotist, and his impulse is to respond immediately. Considerations tending towards a different line of action simply do not occur to him; they cannot, because there is a break in the mind. He cannot review the situation and consider alternatives, and certainly does not even begin to consider them. We see that in hypnosis he has become more suggestible, and that his increased suggestibility, or increased readiness to respond to suggestion, is in part the result of mental dissociation.

But the opposite relationship may hold good. Instead of suggestibility following upon the state of hypnosis, we may find a state of hypnosis following upon suggestion. Indeed, this is what generally occurs when a person is hypnotized. The hypnotist suggests to the person that he will become more and more drowsy, more and more lethargic, but that he will continue to hear and understand what the hypnotist says to him, so that through suggestion from the hypnotist dissociation takes place. A person is robbed of the power of controlling his mind as a unitary system.

The procedure in the case of a patient requiring hypnotic treatment is as follows. After a preliminary general examination-that is, a physical examination and a psychological investigation of the conditions under which his illness had set in, which need not take very long, although a detailed psychological examination (autpgnosis) would require many hours-after this analysis, if the patient is considered suitable for hypnotic treatment, the physician asks him to lie down on a couch, to relax his voluntary muscles, * to fix his gaze on a small mirror or

* The patient may be given detailed instruction in the matter of muscular relaxation. If he directs attention to the small distal muscles of hands and feet he will find that relaxation of them tends to spread to the larger muscles of the arms, legs, etc. Deep and
regular breathing also helps relaxation. 
other luminous object held about ten inches from his eyes and slightly above the horizontal plane of vision-so that he has to turn his eyes slightly upwards and inwards-to look steadily at it, to fix his visual attention on it, and to think of sleep. The hypnotist then proceeds to suggest that the patient is getting more and more drowsy-that his eyelids are getting heavy with sleep-that he will soon be asleep, but will continue to hear what the hypnotist says to him. The patient's eyes close and he appears to sleep. The hypnotist may then suddenly hold his attention by speaking more urgently and more dramatically, saying. "Yon may try as hard as you like, but you cannot open your eyes." The mere fact that he is challenged in this way makes him suddenly lose the knack; there arises the momentary fear, "Perhaps I shall not be able to open my eyes," and that momentary fear prevents him from opening them. He gets into a slightly emotional condition, and is ready to believe other statements made to him. If passes (with or without contact) are made down the $\mathrm{arm}$ and hand, with suggestions of rigidity and anaesthesia, the arm does become rigid so that the patient is unable to bend it, and it also becomes anaesthetic, so that a sterilized pin may be plunged deep into the flesh without causing any pain. In a deeper stage still the patient may become apparently quite unconscious, although subsequent investigation may show that he has retained an inactive dream-like consciousness throughout the experiment.

Hypnosis seems to proceed in stages, of deeper and deeper degree; but nowadays we do not speak of stages of hypnosis, because they have no definite order of sequence.* "We find that the order in which they occur depends to a very large extent upon the way in which, or the conditions under which, suggestions are given. The patient falls into a hypnotic state, and in that state becomes more suggestible, more ready to respond to suggestions, verbal or otherwise, from the hypnotist, and these suggestions may be used to increase the depth of the hypnosis. One stage in a good hypnotic subject is that of waxy or plastic flexibility, where the limbs, put in any position, remain in that position like the limbs of a lay figure. This stage, like those previously described, is a state of dissociation. Indeed, most, if not all, of the phenomena of hypnosis seem to be phenomena of dissociation. The simplest is the patient's inability to open his eyes; again, if he clasps his hands together and is then told by the hypnotist that he will not be able to separate them, he cannot do so. A further result of a dissociationist nature which it is very easy to produce in a hypnotic subject is amnesia. If it is suggested to the subject that he cannot recall anything that happened-for example, during the previous day-it will be found later that he is mable to answer any questions about this period of time. These are all instances of dissociationdissociation of the power of recalling certain memories, of the power of contracting certain muscles, of experiencing certain sensations.

In a still deeper stage of hypnosis the hypnotist may seem to produce positive results instead of merely negative ones. If he suggests to a patient in a deeply hypnotized state that the latter will be able to see, say, a bright red light, the suggestion will take effect. What has happened is that the patient's imagination has been stimulated, has been set in motion, and continues working actively in a certain direction. You can take a blank card and tell him that you are going to show him your photograph, and he will see your photograph and describe it; and really, so far as can be made out, he does actually see something on the card. He projects on the card something that is merely in his own imagination. Here the difference between the hypnotized subject and the normal person is mainly a difference in the degree of activity and control of the imagination. When a person is hypnotized his imagination may become more active, but is under the control of the hypnotist; indeed, all hypnotic suggestion may be considered as an influencing of the imagination. The manifestations previously described may be regarded merely as the effect of an externally controlled imagina-

* The belief in a definite order of sequence of such stages was one of
the errors of Charcot and the Salpêtrière shool tion. An individual has been made to imagine that he cannot open his eyes; nothing having arisen to counter that imagination, it takes effect. The normal person can call up a fairly accurate picture of another individual, but to see it at a definite spot and with a certain degree of steadiness may follow upon hypnosis, where the imagination is controlled by the hypnotist. It is not that the hypnotist has any occult power (magnetic, telepathic, or what not), but that his words and gestures call out a direct and inevitable response from the patient. The patient is ready to believe and expect that what the hypnotist says will come to pass.

Various theories have been devised to account for this, and I shall discuss some of them later on. One well known theory is that of Freud-that these results follow because some bond of affection has sprung up between the hypnotized patient and the hypnotist. The patient responds to the suggestions of the hypnotist much as a young child would respond to the suggestions of a well loved parent or nurse, in primitice credulity without afterthought or other consideration. Another theory is that in the process of hypnosis the patient has been thrust into a state of selfabasement, with the result that he is ready to accept orders from another person. This is McDougall's view : that the patient is specially ready to respond to the hypnotist because, under hypnosis, his instinct of self-abasement has been aroused to the exclusion of other instincts and tendencies. In hypnotized people McDougall assumes that the instinct of self-assertion is in abeyance. Such a theory is based on the conception of dissociation-dissociation at a very fundamental level of the mind-namely, dissociation of one instinctive disposition from the others.

Dissociation may increase suggestibility, or be increased by it. A person may for the moment "forget" how to use certain mental powers, and then through fear become permanently incapacitated, or he may succumb to suggestions in other directions; or, again, he may fall into a state of dissociation, not through mental suggestion from anyone, but through some strong mental or physical shock. During the war large numbers of soldiers became readily hypnotizable under the influence of intense physical shock, either from shell concussion or from blows on the head received in other ways (falls, etc.). It is often difficult to exclude the effect of mental shock in these cases; but instances of purely physical shock, followed by dissociation, do occur. A person who gets physical concussion is almost invariably easy to hypnotize. This concussion probably brings about physical dissociation of the higher centres of the brain. The harmonious activity of the brain as a unit seems to be disturbed by such a general " shaking up." Drugs, such as alcohol, may produce a similar effect. Alcoholic persons are very easy to hypnotize, which is fortunate, because hypnotism can be used in curing them. An alcoholic person may appear to be absolutely incorrigible, but, to his surprise, he finds that he obeys suggestions under hypnotism. Anaesthetics, such as ether or chloroform, will also make a person more readily hypnotizable, and there is good reason for believing that they produce relative dissociation in the highest cerebral levels. Hypnotism was originally used for operations, and if chloreform had not been discovered shortly afterwards, no doubt hypnotism would have been used much more extensively for that purpose; it still has its uses to prepare and calm the patient's mind for an operation. It is very important that a patient, before undergoing an operation, should have his mind free from fear, should control his feelings, and not struggle against the anaesthetic. One of the best ways of bringing this about is to give him suggestion treatiment beforehand, and I have done this in many cases. It has very definite effects; among others, it may save the patient from nausea after the anaesthetic. In many cases where the patients have dreaded the anaesthetic more than the operation, suggestion treatment has freed them from this fear.

It is a fact that in hypnosis the patient falls into a special state in which he responds readily to suggestions from the hyprotist, and to a great extent the characteristics of the hypnotic state seem to be explicable in terms of suggestibility. The patient becomes more suggestible to the hypnotist, and on this basis Bernheim formulated 
his definition of hypnosis as a siate of artificially increased suggestibility. A hypnotized person is made more suggestible than a normal person. But such a definition is not fully adequate to the facts, because it does not explain sufficiently how the increased suggestibility is brought about. Although in some asses sugrestion from tho physician or hypnotist produces the hypnotic state, in other cases, as we have just seen, nevtal shock and phrsical infiuences-such as phrsical concussion, the infuence of drugs, etc--may increase suggestibility or hypnotizability, and certainly it must not be forgotten that ciissociation itself increase's suggestibility; that was forced upon us by the experiences of the war. Among the thousands of shellshock patients seen just behind the lines in France and elsewhere, 15 per cent. showed functional amnesia to a greater or less extent. These patients were in a dissociated state, and in many cases had not only lost the powei of recalling their frightening experiences, but had also lost the power of speaking, hearing, walking, of controlling tremors, and of bringing them to an end. There was a sort of general dislocation of the mind as well as of the nervous srstem. I found that these patients were easily hypnotized, and that the more pronounced the rissociation the more easily were they hypnotized. A man who had lost all his past memory could be hrpnotized at once; a wave of the hand would effect this mental transformation. If the loss of memory referred to but a brief period of the past, the hypnotic state would not set in quite so readily, but every case of amnesia or dissociated memory was in some degree hrpnotizable. Amnesia does not mean weakness of memory, but a loss of the power to recall a definite stretch of past experience. I observed six hundred cases of amnesia in France during the war; every case was hypnotizable, and memory invariably returned under hypnosis. Patients seen in England some months or years later were not so easy to cure; they responded less readily, but they did so eventually, nevertheless.

I am inclined to state as a general rule, admitting of no exception, that a person showing functional amnesia, without psychotic symptoms, is easily hypnotizable, and that in functional amnesia the loss of memory is easily cured by hypotism, as well as any accompanying paralysis - mutisn, etc. of a functional nature. Facts such as these make it necessary to widen the definition of Bcrnheim, and to recall the earlier definition of Charcot, who used to say that hypnosis was an artificial hysteria. We need to combine the two theories (with certain omissions), and say that in the hypnotic state suggestibility is increased, but that a fundamental factor, to some extent of independent value, is a state of dissociation which works in harmony with suggestion; dissociation tends to produce increased suggestibility. The reason of this is obvious. If a person is dissociated he has no power of reviewing the situation and considering alternative modes of response. A certain mode of response is suggested to him, and he makes that response, but because of his dissociation he is unable to actuate other powers of the mind. The dissociation is not the same as increased suggestibility, for we can inagine a relatively normal person, a unified person, showing different degrees of suggestibility at different times. Moreover, although in mild forms of dissociation suggestibility seems to increase as the degree or extent of dissociation increases, this correlation does not hold for extrenie cases. When the dissociation is extreme, or the state of hymosis very deep, the patient may be found to have become less rather than more suggestible to outside influene, or even non-suggestible in certain directions.

The extremely important work of I. P. Paylor on Conditioned lieflexes should be referred to here. Parlov explains sleep and hypnosis in terms of intrrual inhibition in the cerebral cortex-spreading to the subcortical centres in the case of the former, limited to the cortex in the case of the latter.

\section{II.}

We have now to consider in more detail the factor of rapport, which is of such central importance in the theory and practice of hypnotism.

We have already gone beyond the earlier view of hypnotic suggestion, according to which it is regarded as a form of ideo-motor action, where, as Pieire Janet says, the sigrested idea produces its full or maximum effect undisturbed by conflicting ideas. This theory is not sufficint, but itself requires further explanation. An idea, to produce an effect, needs to be in relation with some source of energy. Such a source of energy is any one of the instinctive "urges." or other conative and affective tendencies. According to Freud's theory, the affective tendency concerned is of an erotic or sexual nature--not the tendency of ordinary sexual love, but a sexual tendency inhibited in its aim (zielgehemmte), manifesting itself in a readiness to reiy completely upon the hypnotist, to bo at one with him, and to grant him vigorous and wholehearted co-operation. This is the well known factor of "transference" (lebertragung), so named because it is believed by Freud to be a reanimating of affective tondoncies felt by the voung child towards his elders in the bosom of the family. Freud quotes with approval Ferenczi's observation that there are two main and contrasted methods of hypnotism-namely, the method of command and the method of soothing and coaxing. The former corresponds to the attitude of the father towards the child, the latter to the attitude of the mother. [Compare Pavloy's purely physiological distinction of (1) monotonous stimuli of small and medium intensity repeated for a long time, producing hypnosis slowly, and (2) stimuli of considerably greater intensity, producing hypnosis quickly (in animals).]

At first sight all suggestion seems to be in essence autosuggestion, since it must be accepted by the patient if it is to work at all; the patient has to make the suggestion his own. But there is the converse possibility that all suggestion may be hetero-suggestion-that the individual may never be able to accept anything from himself, but must always accept it from without, either from people or from the books he reads or from physical events in the outer world; so that even auto-suggestion would be heterosuggestion. The person who applies Coués method of autosuggestion, and benefits thereby, owes his success to the influence that Coué has had upon him, the lectures he has heard, and the books he has read. How can this be brought into line with the Freudian doctrine of heterosuggestion? Frnest Jones has recently attempted to solvo this problem in an important article on "The nature of auto-suggestion." He follows Freud in maintaining that the success of hetero-suggestion is due to the re-arousal of early feelings towards the father, in which the hypnotist is put in place of the ego-ideal or super-ego, which, as distinct from the ego, is modelled upon the father. The doctrine of Freud is that in earliest years a little boy loves his father according to the narcissistic or identification type of love-he identifies himself with his father; but he loves his mother according to the dependence or "anaclitic" type, because his various physical wants are satisfied through her. $t$ His love for his mother involves the desire to have her to himself, which arouses, by reaction, a feeling of hostility towards his father. This feeling of hostility towards his father is then repressed, by virtlie of his previous identification with his father, and thus is inaugurated the contrast between the ego and the ego-ideal or super-ego. He incorporates in his own mind the character of his father as he sees him, and if he represses this hostile fecling towards his father, and develops a bid conscience about it, that bad conscience corresponds to a conflict between his ego and his ego-ideal. The child incorporates in himself the disapproval of himself which he must assume that his father would feel if his father knew. Thus the ego-ideal in his own mind corresponds with his wnception of his father. When a person is hypnotized, and accepts suggestions from the hypnotist, he puts the hypnotist in the place of his coo-ideal.

In autu-suggestion, according to Ernest Jones, there is a

* "If the primary narcissism has been roleased and rcanimated directly, by concentration upon the idea of self, the process may be termed 'auto-suggestion'; if it has been preceded by a stage in which the ego-ideal is resolved into the earlier father-ideal, the process may be termed' het
vol. iii, p. 209.

+ More accurately, because “ in the first phase of their development the sexual instinets have no independent means of finding satisfaction they do so by propping themselves upon or "leaning up against the self-preservative instinets." -S. Freud, Group Psychology and the Analysis of the E Eo. Eng. Trans., p. 61, International Psycho-analytical Press,
London, 1922. 
regression-a stepping back to a still earlier psychological situation, a situation of primary narcissism. Before the ego-ideal has been formed the child's sexual energy, his libido, is centred on himself. It is so in earliest years when he identifies himself with his father; there the libido remains fixed on himself. In the practice of auto-suggestion an individual is returning to this earliest stage and concentrating upon the idea of himself. Thus the ego-ideal is reduced to the father-ideal in the case of hetero-suggestion, and reduced still further back to the narcissistic fixation on self in autc-suggestion, which is an intensification of primary narcissism, a pronounced form of regression, and therefore bad. It means an impoverishment of the ego, the withdrawal of much energy which should be available for getting into touch with the world around and the people around, and which should enable him to live his life and make his contribution to general existence; it is a drawing of the libido back upon himself. If Ernest Jones's theory, as a further development of Freudian doctrine, is correct, it is not easy to understand the beneficial results of auto-suggestion. The improvement in physical health is not easy to explain on this theory, nor the fact that the more normal and healthy the person is, and the greater his powers of concentration, the more effective is the practice of auto-suggestion in his case. In functional illness therapeutic auto-suggestion helps to restore the patient to health, and may also greatly improve his general mental outlook on life.

Here I would urge that, as used to indicate a form of psychotherapy, auto-suggestion is an inadequate and misleading term. If we take it literally we have something which usefully indicates the pathological effects of bad autosuggestion-the way in which a person may become ill through his imagination, or become more severely ill than he need. But the term does not satisfactorily indicate the nature of therapeutic suggestion as a correction and improrement of function. Any regression to narcissism must also mean a stepping back from the state of health and a movement towards some form of illness. It might be urged that improvement through auto-suggestion is apparent rather than real, and that actually there is an impoverishment of the mind-that what a person gains is gained at too great an expense. But we do not find that those who benefit by auto-suggestion become more self-centred; on the contrary, they become more self-confident and more free from fear of disease. Moreover, as I have argued elsewhere, ${ }^{1}$ auto-suggestion in its literal form is only a stage in a process of mental development towards an adequate form of volition. Instead of being distinct from volition and a rival of volition, it is a contributory factor in complete volition. An individual who is the prey of bad auto-suggestion in a certain direction is suffering from diminished power of will in that direction. When treated by therapeutic auto-suggestion, that disability is removed. The belief and faith in himself, which is essential to conplete volition, is restored to him. Belief and faith in one's self is auto-suggestion; but this is not to be identified with narcissistic fixation upon oneself. There is no reason for bringing in libido here. The instinct of self-assertion has its own form of energy, quite distinct from the libido of the sex instinct, and contrasted with it as the spirited principle (rò $\theta v \mu o \epsilon \iota \delta \dot{s}$ ) is with the appetitive principle (rò é $\pi \imath \theta v \mu \eta \tau$ ז́óv) in Plato's Republic.

McDougall explains hetero-suggestion in terms of the instinct of submission, or of self-abasement. The patient under the dominance of this instinct surrenders his own views and accepts the views of another person. In the presence of the hypnotist his instinct of selfassertion is in abeyance, and he succumbs completely to the promptings of the instinct of self-abasement. As a theory of suggestion this view seems too limited. The operation of any instinct-powerful, profound, and independent of other instincts-will increase suggestibility and produce suggestion effects. A panic-stricken person will respond vigorously to suggestion of danger; if angry, he will readily respond to any suggestion that he is being insulted. A chance remark, of which in other circumstances he would take no notice, he interprets in a special way. Othello, under the influence of jealousy, responds to the suggestions of Iago, without any help from "transference" or self-abasement. Not only individual instincts, but also individual sentiments* (not to mention complexes), functioning in relative dissociation from the rest of the mind, may be responsible for pronounced suggestion effects. It is really a tour de force on Freud's part, and quite unnecessary, to argue that the affective tendency is ultimately always of a sexual nature, even when the word sex is used in its very widest sense and care is taken to add that the sex tendency is "inhibited in its aim." We can accept transference as a factor; we can believe that an individual may respond in an unconscious way to personal influence, after the type of his response in early childhood to his father and mother; but if a suggestion effect is response independently of reason (though not necessarily contrary to reason) this may occur through the activity of other instinctive forces besides that of the libido.

McDougall has defined suggestion as the acceptance of a statement or of an idea independently of logically adequate grounds for such acceptance. According to this definition, whenever we consciously act according to reason we are acting independently of suggestion, whereas when we act independently of reason (though not necessarily contrary to reason) we are acting according to suggestion. We know what is meant by acting according to reason. "The desire to do what is right and reasonable as such" (Henry Sidgwick) is a definite factor in our lives, and whenever we act in that way we are relatively free from suggestion. According to McDougall's definition, apart from that, all our action is under the influence of suggestion. Neither the sexuol factor postulated by Freud nor the instinct of self-abasement on which McDougall himself relies exhausts the possibilities of explanation. Among other affective tendencies, of special importance in this connexion, there is the gregarious instinct, or "urge" to act in harmony with one's fellows. Freud interprets the action of this instinct in terms of the libido; he holds that the gregarious instinct explains nothing, and is itself in need of explanation. What happens in the action of the group is that there spring up libidinal relationships between members of the group towards one another, and in all of them towards the leader of the group. He proceeds to sketch out a far-fetched theory to explain how this situation arose in prehistoric times-an explanation in terms of the original family as a horde of people living together and ruled by an all-powerful father. His doctrine is that this all-powerful father of the horde is himself merely narcissistic and self-assertive; he does not need to love anyone else, his libido is fixed upon himself; but through his persecution of the sons of the family, and his suppression of them, by thwarting their sex tendency, he in some mysterious way makes them love one another and love him, and so brings about the beginnings of morality and the group spirit. For this extraordinary theory no evidence is supplied.

Freud sums up his theory of love, hypnosis, and the herd instinct in the following sentences:

" Bcing in loce is based upon the simultaneous presence of directly sexual tendencies and of sexual tendencies that are inhibited in their aims, so that the object draws a part of the narcissistic ego-libido to itself. It is a condition in which there is only room for the ego and the object.

"Hypnosis resembles being in love in being limited to these based and tendencies th are inhibited in their aims, and substitutes the object for the ego-ideal.

"The Group multiplies this process; it agrees with hypnosis in the nature of the instincts which hold it together, and in the replacement of the ego-ideal by the object; but to this it adds identification with other individuals, which was, perhaps, originally made possible by their having the same relation to the object."S. Freud: Op. cit., p. 125 .

Without denying all truth to Freud's theory of love, hypnosis, and gregariousness, I must say that my own experience of the facts, gained through use both of the method of suggestion and also of the method of deep analysis in investigating and treating cases, does not bear out the theory in its entirety. The theory is not adequate to cover all the facts. I find similar difficulties with Ernest Jones's theory of the nature of auto-suggestion. I can quite see how regression towards the narcissistic level

* A sentiment is an organization of instinctive-emotional dispositions centred about the idea of some object.-Shand. 
may occul-how an individual may hide his head in the sand and refuse to face reality, crying peace when thero is no peace; but that he would get beneficial results of a permanent nature by such a line of conduct is another matter. An appeal to narcissism might explain the state of mind of a man who stands in the corner of an asylum ward, taking no notice of anyone, but just immersed in his own fancy and in his own mental aberration; or the state of mind of the hypochondriac, with distribution of libido so disturbed that even his bodily organs cannot function adequately or without pain. But that good, or therapentic, auto-suggestion is of this nature I cannot believe. Autosuggestion is based on confidence and the abolition of fear. The individual who uses auto-suggestion knows this, and it is definitely admitted that auto-suggestion works better in a more healthy person; the healthier he is the better effects he can get. Auto-suggestion is a method of will training.

In holding such a view the possibility is not excluded that in hypnosis archaic affective tendencies and beliefs may come to the surface and make themselves felt, and that an individual may produce certain results by virtue of the strength of these primitive beliefs which are not justified by modern scientific knowledge, although such beliefs may make a great difference to the individual himself. In him there may be a desire for the miraculousa desire to believe in the miraculous-which may be liberated under conditions of hypnosis, or suggestion treatment, and may produce results; not that it will produce a miracle, but it may counteract the excessive scepticism and doubt and despair which are so often characteristics of the modern mind. Consequently, bad, or pathogenic, auto-suggestion is perhaps the best example of autosuggestion in a literal sense-that is, the working of an idea under the influence of an instinctive tendency, in this case one of fear and apprehension. Frend might say that fear is due to bad conscience, and that bad conscience is due to the working of the Oedipus complex, so bringing in the libido doctrine. Therapeutic auto-suggestion goes further, because it replaces the feeling of doubt and fear by a feeling of confidence. The result suggested can then occur, so far as it does not conflict with any of the fundamental laws of nature, and can occur to a maximum degree. The instinct of self-assertion (supported by its own distinctive form of energy, not by libido) may play a prominent part in bringing abont a realization or actualization of the suggestion; but the integrated personality, with its entire reserves of instinctive energy, mav, by an act of faith, fulfil more adequately the purposes towards which auto-suggestion is half blindly pointing.

REFERENCE

1 Mind and Personality, University of London Press, Ltd., 1926, pp. 180, 272.

\section{THE CAUSATION OF “STRIAE ATROPHICAE CUTIS" ("VERGETURES") NOT DUE TO STRETCHING OF THE SKIN. BY}

\section{F. PARKES WEBER, M.A., M.D., F.R.C.P.}

IN all ordinary cases striae atrophicae or striae cutis distensae can be explained as representing a method of cutaneous accommodation towards distension (physiological or pathological), when the skin is relatively insufficient-that is to say, unable to adjust itself by its normal elastic distensibility. In such cases a relatively too rapid growth or increase in bulk of the parts below the skin, or a cause of chronic distension of some kindsuch as a relatively excessive growth of subcutaneous fat, muscle, or long bones (especially connected with puberty), mammary gland, the pregnant uterus, ascites, tumouis, or subcutaneous oedema-leads to a splitting or cleavage in the deeper parts of the cutis, manifested on the surface by the appearance of striae atrophicae, which are at first red or purplish, and in time gradually become white and smaller as they heal up.

In the present note I shall refer only to those cases of striae atrophicae not due to stretching of the skin; that is to say, the cases in which striae atrophicae have developed apparently in the absence of any special distension-in the absence of pregnancy, ascites, tumours, subcutaneous oedema, excessive subcutaneous fat, and other usual causes. In such cases the ordinary growth of the long bones, muscles, and subcutaneous fat seems to be associated with some insufficiency of the cutis (with perhaps deficiency of elasticity) which prevents the skin from adjusting itself to the parts beneath, excepting by the process of multiple cleavage-that is to say, by the formation of striae atrophicae. Striae atrophicae of this mysterious kind occur occasionally in apparently healthy individuals about the period of puberty, the skin failing to keep pace with the normally rapid growth of certain parts of the body, such as the shoulders, pelvis, and thighs. Striae atrophicae, in the absence of ordinary causes, are, however, still better known to occur in connexion with enteric fever (notably the "striae patellares") and certain other microbic infections, although even in such cases the selective distribution of the striae, and whether they are symmetrical or more or less unilateral or not, as I have elsewhere endeavoured to explain, must be due partly to mechanical causes, such as the position of the patient in bed, arrangement of pillows, etc. ${ }^{1}$

What is the cause of the relative insufficiency of the cutis in these cases to which $I$ am referring?

Heve I must speak of a condition of abnormal relative or absolute redundancy of the skin which may be contrasted with, and in some respects is the opposite of, the relative or absolute cutaneous insufficiency manifested by striae atrophicae. I refer to cutis striata or cutis sulcata -that is to say, ploughed or furrowed skin-_" bulldog scalp," and cutis verticis gyrata. In these cases the scalp, especially the skin of the scalp, is locally altogether too big for the skull beneath it, and has therefore to become folded into ridges and furrows, so as to adjust itself to the surface which it covers. A local suboccipital variety of furrowed scalp may be etiologically connected with shortness of neck, ${ }^{2}$ and in certain idiots complete furrowed scalp has been associated with more or less microcephaly, though I think the microcephaly was insufficient entirely to account for the scalp condition.

In twelve cases, howerer, the general redundancy of the skin and subcutancous tissue of the scalp which gave rise to a condition of cutis verticis gyrata was connected with acromegaly, ${ }^{4}$ and was doubtless a manifestation of the functional (hormonic) over-activity of the anterior lobe of the pituitary gland, which is the essential cause of the main features of acromegaly, including skeletal and visceral overgrowths. Though cutis verticis gyrata occurs in relatively fow cases of acromegaly, it must nevertheless, when it is present, be regarded as a manifestation of the acromegalic process, just as enlargement of certain viscera (" splanchnomegaly") must, though likewise not occurring in every case.

I suggest that, as the redundancy of the cutis present in certain cases of acromegaly is obviously due to excessive hormonic activity of the anterior lobe of the pituitary gland, or of an adenomatous tumour (an "endocrine-tumour") arising from it, the insufficiency of the cutis manifested by striac atrophicae cutis, when not caused by special distension, may be due to a defective hormonic activity of the same endocrine gland, for which, perhaps, a depressing action of the toxins of enteric fever and other microbic infections may be sometimes responsible. This suggestion is in accordance with the occurrence of obesity (of a cerebral or pituitary type) occasionally observed as a sequel to enteric fever and other microbic infections.

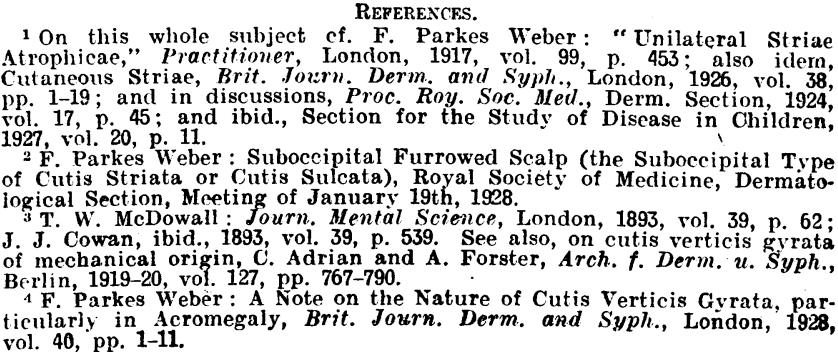

